УДК 663.14. 033, 663.143.2

\title{
ВЛИЯНИЕ МЕХАНИЗМОВ ДИВЭ НА СКОРОСТЬ МАССОПЕРЕНОСА И РОСТ МИКРООРГАНИЗМОВ
}

\author{
Ободович А.Н., Д.т.н, Фищенко А.Н., к.т.н., Сидоренко В.В. \\ Институт технической теплофизики НАН Украинь,, ул. Желябова, 2а, Киев, 03680, Украина
}

В статье приведены данные экспериментально-теоретических исследований скорости массопереноса кислорода в культуральной жидкости при культивировании хлебопекарских дрожжей.
У статті наведені дані експериментально-теоретичних досліджень швидкості масопереносу кисню в культуральній рідині при культивуванні хлібопекарських дріжджів.
The article presents data of experimental and theoretical investigations of the mass flow rate of oxygen in the culture medium during cultivation bakery yeast.

Библ. 3, рис. 4, табл. 2.

Ключевые слова: скорость массопереноса кислорода, скорость потребления, удельная скорость роста дрожжей.

Культивирование микроорганизмов имеет большое значение в разных отраслях промышленности и биотехнологиях [1]. На рост микроорганизмов влияет большое количество различных факторов [2]. Для аэробных микроорганизмов важное значение имеет аэрирование среды. Аэробные микроорганизмы используют для дыхания только растворённый (абсорбированный) в среде кислород. Снижение в среде растворённого кислорода ниже критического уровня ведёт к замедлению их роста и гибели.

В предыдущих исследованиях было изучено растворение кислорода в воде и питательных средах при обработке в ферментёре с дискретноимпульсным вводом энергии. Эти исследования проводились с питательными средами (без потребления кислорода микроорганизмами). Присутствие микроорганизмов в питательных средах будет постоянно снижать содержание кислорода и питательных веществ. Последние будут расходоваться на обеспечение жизнедеятельности клеток.

Поэтому более актуальным становится вопрос не о концентрации растворённого кислорода в культуральной жидкости, а о скорости его растворения.

В связи с этим целью данных исследований является изучение влияния механизмов дискрет- но-импульсного ввода энергии на скорость растворения кислорода, коэффициент массопереноса и удельную скорость роста микроорганизмов.

В качестве объекта исследований использовались дрожжи расы Saharomices cerevisae.

Культивирование проводили на водных растворах мелассы с добавлением минеральных источников азота и фосфора, ph среды регулировался добавлением ортофосфорной кислоты.

Культивирование дрожжей осуществлялось в ферментёре с дискретно-импульсным вводом энергии, разработанным в Институте технической теплофизика НАН Украины [3].

Для определения скорости растворения кислорода применяли уравнение массобмена

$$
K_{D}=\frac{d c}{d t}=\beta \cdot F(\mathrm{Co}-C)
$$

где $K_{D}-$ скорость абсорбции кислорода, кг $\mathrm{O}_{2} / \mathrm{M}^{3} \cdot$;

$C o$ - концентрация кислорода в жидкости при полном насыщении ее, которое может быть достигнуто при данной температуре и парциальном давлении кислорода в продуваемом воздухе, кг $\mathrm{O}_{2} / \mathrm{M}^{3}$

C- фактическая концентрация кислорода в культуральной жидкости $\mathrm{O}_{2} / \mathrm{M}^{3}$;

$\beta$ - константа массопередачи кислорода для данной среды и температуры, м/ч;

$F$ - площадь поверхности раздела между жидкой и газовой фазами, $\mathrm{M}^{2} / \mathrm{M}^{3}$. 
Скорость абсорбции кислорода, как видно из уравнения (1), может быть увеличена соответствующим увеличением одного из сомножителей $\beta \cdot F$ или $(\mathrm{Co}-\mathrm{C})$. Движущая сила процесса абсорбции, определяемая разностью равновесной и рабочей концентрации растворённого кислорода, возрастает с уменьшением рабочей концентрации. Для того, чтобы обеспечить большую движущую силу процесса абсорбции и больший приток растворённого кислорода в культуральную жидкость, целесообразно вести процесс с наименьшей рабочей концентрацией кислорода. Наименьшая рабочая концентрация кислорода должна быть выше критической, т.е. не лимитировать скорость потребления его дрожжами. Для дрожжей, выращиваемых на мелассной питательной среде, она составляет, как правило, около $0,5 \mathrm{мг} /$ Л.

В уравнении (1) произведение $\beta \cdot F$ можно заменить символом Kla, обозначив его, как коэффициент массопрередачи $\left(\mathrm{ч}^{-1}\right)$. Тогда уравнение (1) примет вид

$K_{D}=K l a(\mathrm{Co}-\mathrm{C})$.

В соответствии с уравнением (2) скорость абсорбции кислорода воздуха в культуральной среде рационально регулировать в аппарате изменением величины коэффициента массопередачи в зависимости от потребностей дрожжей. Значение Kla можно повысить, обрабатывая среду в роторно-пульсационном аппарате, используя механизмы дискретно-импульсного ввода энергии.

Процесс культивирования дрожжей может успешно осуществляться только при условии достаточно интенсивного массообмена во всех точках рабочего объёма аппарата, т.е. в аппарате полного смешения по жидкой фазе, когда во всём объёме аппарата для каждого произвольно выбранного момента времени любой из параметров процесса, включая коффициент массопередачи, принимает одно и тоже значение. Для решения поставленной задачи был создан ферментёр с дискретно-импульсным вводом энергии.

При определении коэффициента массопередачи было принято, что скорость растворения кислорода - равна скорости его потребления клетками $K r$, т.е. выполняется равенство $K_{D}=K r$.

Растворённый в жидкости кислород потребляет- ся дрожжевыми клетками со скоростью

$K r=q \cdot x \cdot \mu$,

где $q-$ потребность в кислороде для синтеза АСД. г $\mathrm{O}_{2} / \Gamma$

$\mu$ - удельная скорость роста дрожжей г/Г·ч, или $\mathrm{ч}^{-1}$;

$x$ - концентрация дрожжей в среде, г/л.

Величины $q, \mu$ и $x$ определяются экспериментально.

Зная, таким образом, значение рабочей концентрации в каждый момент времени, можно определить скорость массопереноса коэффициент массопереноса, которые определяются из уравнения материального баланса:

$K_{D}=K r=K l a(C o-C)=q \cdot x \cdot \mu$.

Откуда

$K l a=(q \cdot x \cdot \mu) /(C o-C)$.

В ходе дальнейших исследований было изучено влияние механизмов ДИВЭ и конструктивных особенностей роторно-пульсационного аппарата на скорость растворения кислорода. Коэффициент массопереноса и удельную скорость роста дрожжей.

На рисунке 1 представлена зависимость скорости массопереноса от угловой скорости вращения ротора при различном содержании сухих веществ (СВ) в культуральной жидкости.

Необходимо отметить, что с увеличением угловой скорости вращения роторов от 38,2 до 52,52 об/с скорость массопереноса увеличивается. Установлено, что скорость массопереноса во многом зависит от концентрации $\mathrm{CB}$ в среде. C уменьшением содержания СВ от 10 до $5 \%$ при обработке с угловой скоростью 47,75 об/с скорость массопереноса увеличивается в 1,9 раз.

При проведении исследований представляло интерес то, как влияет на скорость массопереноса частота пульсаций потока в РПА в зависимости от содержания СВ (рис. 2).

Из рисунка видно, что увеличение частоты пульсаций от 2 до 3,85 кГц ведёт к увеличению массопереноса от 5 до 7,3 г/л·ч при содержании CВ $3 \%$, от 3,5 до 4,8 г/л·ч при содержании СВ 5 $\%$ и от 2 до 4 г/л·ч при содержании СВ $10 \%$. Заметное увеличение частоты пульсаций приводит к “ужесточению” режима обработки, что отрицательно сказывается на динамике роста дрожжей. 


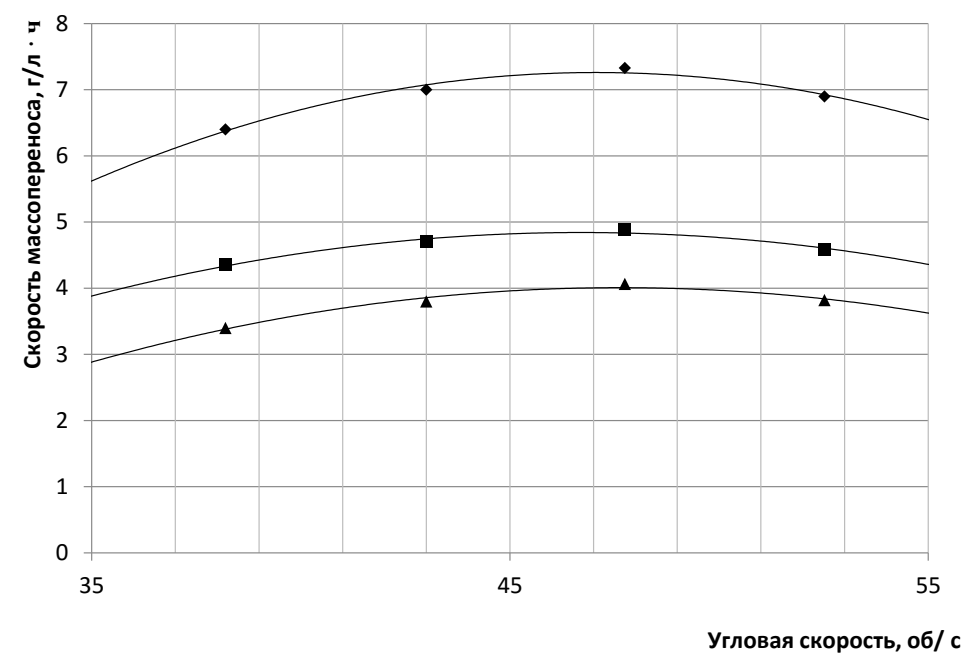

Рис. 1. Зависимость скорости массопереноса от уаловой скорости вращения роторнопульсационного узла при концентрации СВ: $\triangle$ - $10 \%$; - 5\%; - 3 \%.

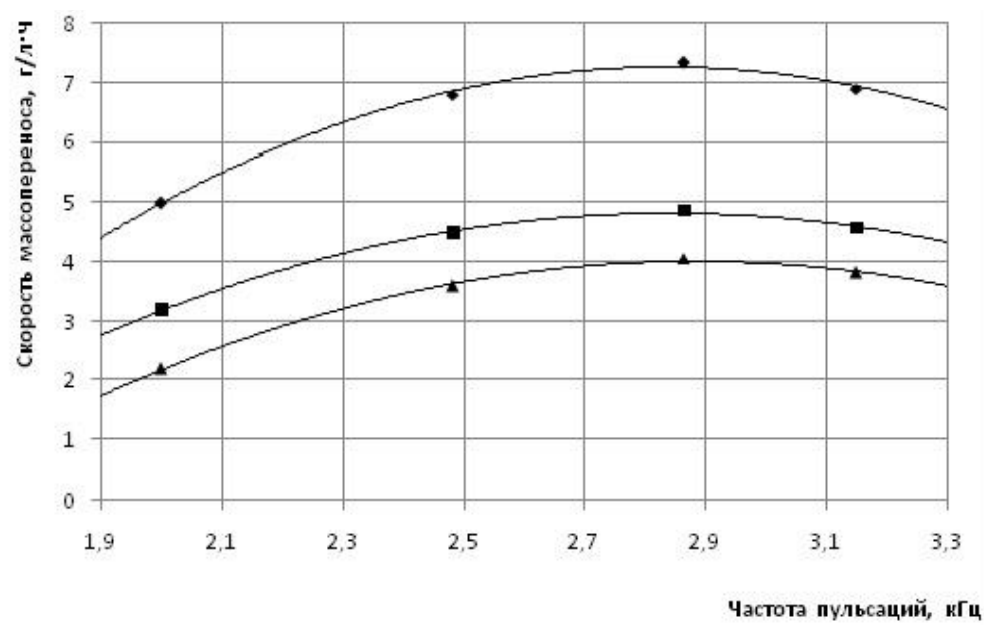

Рис. 2. Зависимость скорости массопереноса от частоты пульсаций потока при концентрации СВ: А - $10 \%$; - $5 \%$; $3 \%$.

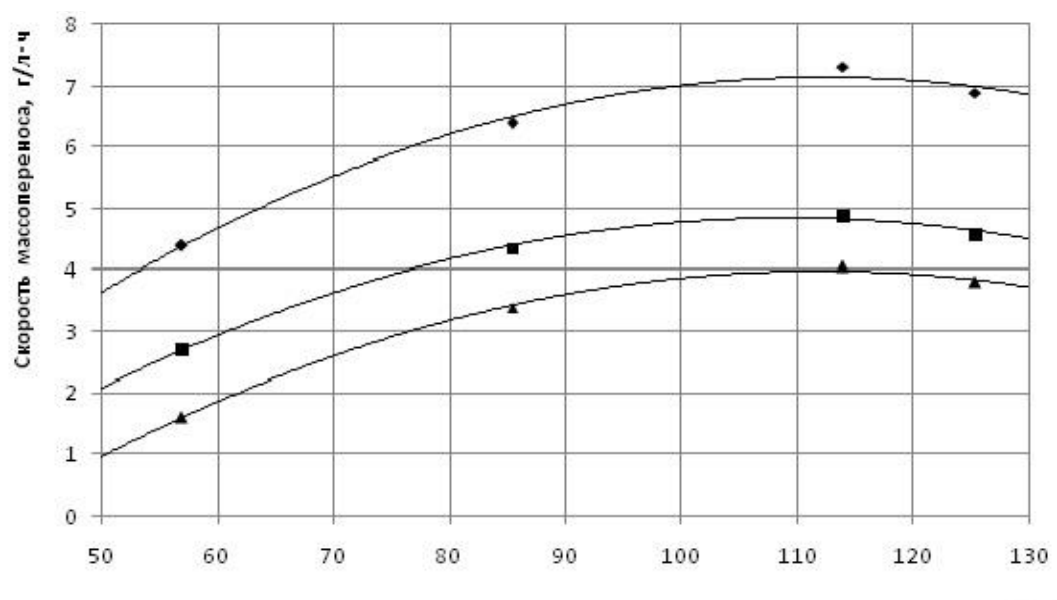

скорость сдвига потока $10^{3} \mathrm{c}^{-1}$

Рис. 3. Зависимость скорости массопереноса от скорости сдвига потока при концентрации СВ: $\triangle-10 \% ;-5 \% ;-3 \%$. 
При определении влияния механизмов ДИВЭ на скорость массопереноса важным фактором является межцилиндровый зазор, влияние которого учитывает такой показатель, как скорость сдвига потока, которая определяется, как отношение скорости потока среды в радиальном направлении в РПА к межцилиндровому зазору.

Экспериментальные данные, отражающие зависимость скорости массопереноса от скорости сдвига потока при различном содержании СВ в среде, представлены на рис. 3 .

Как и в предыдущих исследованиях установлено, что с увеличением скорости сдвига потока скорость массопереноса увеличивается, однако увеличение значения этой величины ведёт к необходимости получения малых (менее 100 мкм) зазоров, что технически трудно выполнимо. Оптимальный диапазон значений скорости сдвига потока лежит в пределах $90 \ldots 100 \cdot 10^{3} \mathrm{c}^{-1}$. Из рисунка так же следует, что с увеличением содержания CВ в среде скорость массопереноса уменьшается.

Проведенные исследования позволяют сделать вывод о том, что скорость массопереноса при выращивании дрожжей в ферментёре с дискретно-импульсным вводом энергии зависит от механизмов ввода энергии и конструктивных особенностей РПА.

Для анализа работы ферментационных аппаратов с различными системами аэрирования ниже приведены их сравнительные характеристики по скорости массопереноса. Характеристики представлены с учётом того, что на аэрирование расходовалось около $100 \mathrm{~m}^{3} / \mathrm{M}^{3}$ ччас воздуха.

РПА работал в непрерывном режиме со скоростью вращения ротора 47,75 об/с, частотой пульсаций - 2,87 кГц, скоростью сдвига потока $114 \cdot 10^{3} \mathrm{c}^{-1}$, концентрации СВ - $10 \%$. Полученные данные представлены в табл. 1 .

Таблица 1. Сравнительная характеристика воздухораспределительных устройств различной конструкции по скорости массопереноса кислорода

\begin{tabular}{|c|c|c|}
\hline № ח/П & Воздухораспределительные устройства & $\begin{array}{c}\text { Скорость массопереноса, } \\
\kappa \Gamma / \mathrm{M}^{3} \cdot \text { час }\end{array}$ \\
\hline & Трубчатые & $1,4 \ldots 1,6$ \\
\hline & Коробчатые & $1,4 \ldots 1,6$ \\
\hline & Турбоаэрационные воздухораспределительные & 1,19 \\
\hline & Вибрационные & 1,8 \\
\hline & Эрлифтной системы & 1,12 \\
\hline & РПА & 4,06 \\
\hline
\end{tabular}

Как видно из таблицы, использование в ферментёре в качестве аэрационной системы РПА позволяет повысить скорость массопередачи более чем в 2,5 раза по сравнению с существующим оборудованием. Такой эффект может объясняться высокой турбулизацией потока, диспергированием пузырьков газовой фазы, увеличением площади контакта фаз.

Количественными и качественными показателями культивирования дрожжей Saharomices cerevisae являются удельная скорость роста, концентрация дрожжей в единице объёма, количество мёртвых клеток.

Одним из главных показателей при культиви- ровании дрожжей является их удельная скорость роста $\mu$ (г/Г·ч) или ч ${ }^{-1}$. В период наиболее активного роста дрожжей (экспоненциальной стадии), удельная скорость роста дрожжей определяется следующим соотношением

$\mu=(\ln (\mathrm{xo} / \mathrm{x})) / \tau$,

где хо - концентрация дрожжей в начале культивирования, г/л

$\mathrm{x}$ - конечная концентрация дрожжей, г/л

$\tau-$ время культивирования, час.

Перед нами стояла задача оценить зависимость удельной скорости роста дрожжей от скорости сдвига потока с различной концентрацией 
CВ. Результаты экспериментов представлены на рис. 4.

Анализ кривых, изображенных на рис. 4, приводит к выводу, что увеличение скорости сдвига потока до $114 \cdot 10^{3} \mathrm{c}^{-1}$ благотворно влияет на удельную скорость роста дрожжей при различной концентрации СВ в среде. С увеличением скорости сдвига потока свыше $114 \cdot 10^{3} \mathrm{c}^{-1} \Gamma$, удельная скорость роста дрожжей начинает снижаться. По мнению авторов, причиной этому могут быть несколько факторов.

Первый заключается в том, что увеличение скорости массопереноса способствует быстрой и большей доставке питательных веществ в клетку, может превышать необходимое для жизнедеятельности. В связи с этим рост клетки замедляется или вообще прекращается. Переизбыток кислорода и питательных веществ в дрожжевой клетке может привести к её гибели.

Следующим фактором является то, что для достижения высокой скорости растворения кислорода необходимы “жёсткие" условия обработки среды в РПА, т.е. высокие угловые скорости вращения роторов, частоты пульсаций, скорости сдвига потока. При этом в межцилиндровом зазоре высокие сдвиговые напряжения, которые могут приводить к разрушению клеточной стенки и гибели само́й клетки.

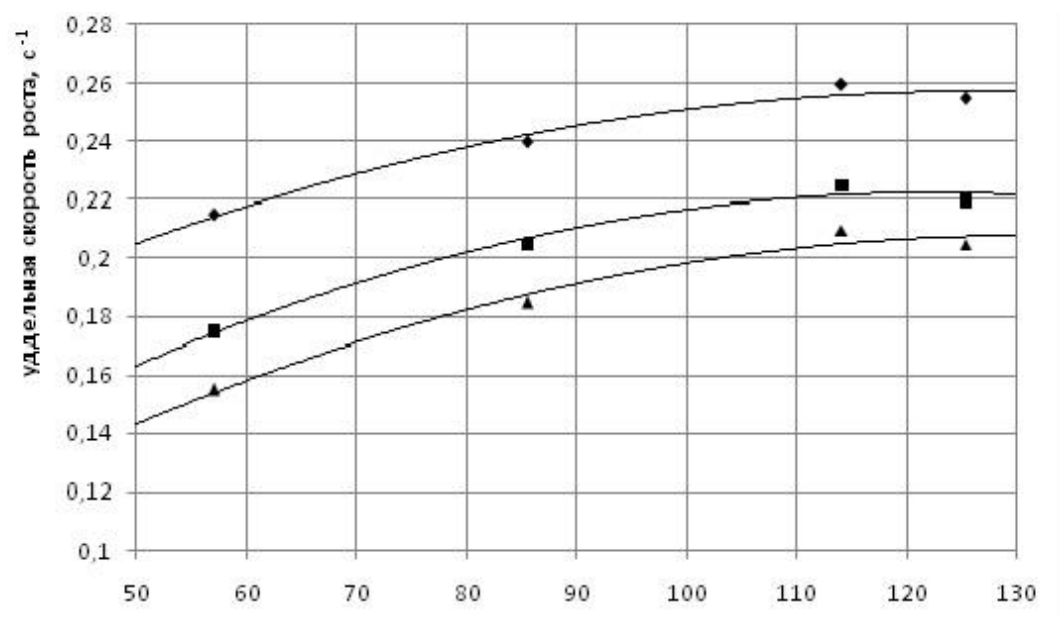

Рис. 4. Зависимость удельной скорости роста дрожжеей от скорости сдвига потока при концентрации СВ: $\triangle-10 \%$; - $5 \%$; $3 \%$.

Таблица 2. Зависимость количества мёртвых клеток от скорости сдвига потока в РПА

\begin{tabular}{|c|c|c|c|c|c|c|c|c|c|}
\hline \multirow{2}{*}{ Скорость сдвига потока в РПА, $10^{3} \mathrm{c}^{-1}$} & \multicolumn{9}{|c|}{ Время культивирования, час } \\
\hline & 0 & 1 & 2 & 3 & 4 & 5 & 6 & 7 & 8 \\
\hline 85,46 & 2 & 2 & 2 & 2 & 3 & 3 & 4 & 4 & 4 \\
\hline 114 & 2 & 2 & 2 & 3 & 3 & 4 & 4 & 4 & 5 \\
\hline 125,4 & 2 & 3 & 3 & 5 & 5 & 6 & 6 & 9 & 10 \\
\hline барботаж & 2 & 2 & 2 & 2 & 2 & 2 & 2 & 3 & 3 \\
\hline
\end{tabular}

С целью подтверждения этих предположений в дальнейших исследованиях было изучено влияние скорости сдвига потока на гибель дрожжевых клеток. Количество отмерших клеток методом микроскопии. Проба культуральной жидкости заполняла камеру Горяева, где подсчитывалось количество дрожжевых клеток. Отмершие клет- ки определялись добавлением в пробу красителя метиленового синего. Результаты исследований отражены в таблице 2.

По полученным экспериментальным данным можно сделать следующие выводы:

- Управляя механизмами ДИВЭ и меняя конструктивные особенности РПА, можно регу- 
лировать скорость массопереноса;

- Увеличение скорости массопереноса до 4,1 г/л·час позволяет интенсифицировать процесс выращивания дрожжей, а именно сократить продолжительность продолжительности процесса с 12 до 7 час и увеличить концентрацию дрожжей в 2 раза по сравнению с существующей технологией;

- Увеличение скорости массопереноса свыше 4,1 г/л·час приводит к снижению выхода готовой продукции; $68 \%$.

- Снижение удельного расхода энергии на ЛИТЕРАТУРА

1. Новый справочник химика и технолога.

\section{A. Obodovich , A. Fischenko, V. Sidorenko}

Institute of Engineering Thermophysics, National Academy of Sciences of Ukraine, Zhelyabova str., 2a, Kiev, 03680, Ukraine

The paper presents experimental data on the rate of mass transfer of oxygen into the culture medium during the growth of bakery yeast in the fermentation method of installing a discrete-pulse energy input. Dependence of the rate of mass transfer of oxygen from the following processing parameters pulsation frequency flow rate of translations is present. Determination of the specific growth rate of yeast at different concentrations of nutrients in the processing unit is present.
Сырьё и продукты промышленности органических и неорганических веществ Ч.2 - С-Пб.: АНО НПО "Профессионал", 2007. - 1134 с.

2. Фищенко А.Н. Разработка технологии дрожжей в производстве спирта с использованием электрохимической обработки питательных сред: дис. кандидата техн. наук / А. Н. Фищенко. - К., 1988. - 191 с.

3. Ободович А.Н. Устройство для оптимизации массообменных процессов за счёт дискретно - импульсного ввода энергии при культивировании микроорганизмов/ А.Н. Ободович, С.И. Костик, В.В. Сидоренко//Енергетика: економіка, технології, екологія. - 2014. - №4. - с. 23 - 26

Key words: mass flow rate of oxygen consumption rate, the specific rate of growth of yeast

References 4

1. The new reference Chemist and technologist. Raw materials and products of industrial organic and inorganic substances - S-Pb.: ANO NPO "Professional", 2007. - 1134 c.

2. Fischenko A.N. Razrabotka tehnologii drozhzhey $\mathrm{v}$ proizvodstve spirta $\mathrm{s}$ ispolzovaniem elektrohimicheskoy obrabotki pitatelnyih sred Doct. Diss [Development of technology in the production of yeast alcohol using electrochemical machining culture media. Doct.Diss ]Kiev, 1988,191 p.

3. A. Obodovich, S. Kostik, V. Sidorenko Device for optimizing the mass transfer processes at the expense of discrete-pulse energy input in the cultivation of microorganisms// Energetika: ekonomika, tehnologiyi, ekologiya. 2014. - №4. P. $23-26$ 